\title{
A CRÔNICA: FORMAÇÃO DE LEITORES NO 9 ANO DO ENSINO FUNDAMENTAL
}

\section{ARTIGO ORIGNAL}

LIMA, Élida Valeria da Silva ${ }^{1}$

CARIA, Josiano Regis ${ }^{2}$

LIMA, Élida Valeria da Silva. CARIA, Josiano Regis. A crônica: Formação de leitores no 9o ano do Ensino Fundamental. Revista Científica Multidisciplinar Núcleo do Conhecimento. Ano 05, Ed. 11, Vol. 02, pp. 131-149. Novembro de 2020. ISSN: 24480959, Link de acesso: https://www.nucleodoconhecimento.com.br/educacao/acronica

\section{RESUMO}

A leitura é o eixo norteador do ensino em Língua Portuguesa e, como tal, precisa tornar-se objetivo de ensino, pois trata-se de um processo cognitivo, histórico, cultural e social de produção de sentidos. Conceber a leitura desse modo remete-nos a pensar em como organizar o seu ensino. Se os sentidos não estão prontos no texto, é preciso contribuir para que os alunos criem boas estratégias para estabelecer relações necessárias à compreensão. Tais estratégias perpassam pelos gêneros textuais e o trabalho planejado através deles, especificamente, a crônica. Os objetivos aqui postulados incluem conhecer essas estratégias de leitura para a formação de leitores críticos dos alunos de uma turma de 9. ano do Ensino Fundamental em uma Escola

1 Pós-graduada Especialista em Psicopedagogia; Pós-graduada Especialista em Gestão Integradora; Graduada em Normal Superior; Graduada em Letras Literatura Brasileira; Formação a nível médio em $2^{\circ}$ grau profissionalizante em Magistério.

2 Orientador. Doutorado em andamento em Humanidades y Artes. Mestrado profissional em Educação e Ensino de Ciências. Especialização em Informática e Educação. Graduação em Licenciatura em Letras- Vernáculo. 
Estadual no Município de Presidente Figueiredo/AM. O método utilizado é o da pesquisa exploratória mista (quantitativa e qualitativa) de caráter indutivo, que nos levou aos resultados elencados, mediante a aplicação de questionários. O tema, longe de ser esgotado, merece ser mais discutido e explorado, uma vez que a formação de leitores críticos é o cerne da questão mais discutida entre especialistas e educadores da Educação Básica.

Palavras-Chave: leitores proficientes, gênero textual, crônica.

\section{INTRODUÇÃO}

Entender a leitura e entender o que é ensiná-la, é refletir e falar sobre ela, é ser um leitor que sente prazer nessa prática, é mediar textos e leitores. Consequentemente, a prática de ensinar a escrever em sala de aula é encarada como uma das atividades mais desafiadoras para professores e alunos, uma vez que está intrinsecamente ligada à leitura, estando no seu distanciamento a sua maior objeção. Os professores, em sua maioria, afirmam que os alunos não têm interesse pela leitura e não gostam de ler e, a consequência é uma escrita pobre ou muito dificultosa. Em contrapartida, muitos alunos dizem que os professores não têm criatividade, sempre propõem as mesmas atividades, do mesmo jeito e de forma tradicional nas aulas de Língua Portuguesa, quando recorrem inevitavelmente, à conhecida redação de vinte ou trinta linhas. A prática da leitura na escola deve partir das próprias vivências do professor, pois formar o hábito da leitura nos alunos não é tarefa fácil. O diálogo deve permear o processo ensino-aprendizagem em torno da leitura e da escrita, tomando como base a vida real, para que haja identificação, sentimento de pertencimento e protagonismo. Neste contexto, o presente tema "A crônica no Ensino Fundamental" refletir sobre como o trabalho pedagógico com as leituras de crônicas, favorece a consciência crítica e a habilidade de escrita em alunos do 9. Ano do Ensino Fundamental, uma vez que as lacunas e carências no ensino-aprendizagem da leitura e da escrita nesse segmento de ensino estão patentes através das divulgações dos resultados das avaliações em larga escala no Estado do Amazonas. 
O porquê do pouco interesse dos alunos em ler textos literários? Como favorecer, através da prática pedagógica, a formação de leitores proficientes? A escrita é favorecida pelo hábito da leitura e, em especial do gênero crônica? A partir desses questionamentos objetivamos, de forma genérica, definir estratégias pedagógicas do processo ensino-aprendizagem para a formação de leitores críticos, a partir do gênero citado, utilizando-o como suporte para o desenvolvimento da produção textual no ambiente escolar. Especificamente ainda, objetiva-se determinar as principais dificuldades na formação de leitores e produtores de textos opinativos dos alunos do 9o ano do Ensino Fundamental; definir os métodos utilizados por professores de Língua Portuguesa, para o desenvolvimento das competências de leitura com o gênero crônica; apontar, a partir da pesquisa, meios para o desenvolvimento e estratégias de leitura, interpretação e escrita de textos no trabalho docente com alunos desse segmento do ensino básico. $O$ trabalho de pesquisa apresenta a metodologia exploratória, com abordagem mista de método indutivo. O instrumento é o questionário qualitativo de perguntas abertas e questionário aos alunos de perguntas fechadas, com variáveis de mostras de parte do universo a ser pesquisado em uma turma de 30 alunos de 9. Ano do Ensino Fundamental e com dois professores da área de Letras da Escola Estadual Maria Calderaro no Município de Presidente Figueiredo.

O tema da leitura adveio não só das inovações no campo intelectual, de pesquisadores brasileiros ligados aos mais recentes estudos linguísticos de outros países, mas também do fenômeno hoje postulado como a "crise da leitura" suscitando o interesse de estudiosos dos mais diversos campos, como o da Filosofia, Psicologia, Sociologia dentre outros, concorrendo para o aprofundamento dos estudos na esfera educacional. A crise da leitura que hora vivemos põe em questionamento a maneira como a escola, instituição educativa formal, vem conduzindo o processo, sem mudanças graduais, sem acompanhar os avanços educacionais num mundo globalizado em que o conhecimento está ao alcance de todos. Assim, é fundamental que nos voltemos para as discussões e trabalho aqui postulados, no intuito de que se oportunize a reavaliação dos fracassos consumados e dos avanços profissionais do ensino alcançados, permitindo aos que lidam ou irão lidar com o dia a dia da sala de 
aula, que sejam habilitados a reconhecer a leitura como uma concepção de vida e não de escola. Tal temática foi abordada no artigo científico Interdisciplinar, Edição Especial ABRALIN/SE, Itabaiana/SE, Ano VIII, v.17, jan./jun. 2013, por Cristiane Menezes de Araújo e Sara Rogéria Santos Barbosa.

A área da Língua Portuguesa foi a escolhida para a realização desta pesquisa, que tem como objetivo refletir sobre as questões de leitura e escrita na Educação Básica. A escola é o espaço para o exercício da liberdade de pensamento e de expressão. É a porta de entrada para a reflexão sobre aspectos importantes do comportamento humano e da vida em sociedade.

É no espaço da interlocução, do pensamento em conjunto, que se assegura a aprendizagem. O papel mais importante do professor, convém ressaltar, não é o de trazer informações e conhecimentos para "repassá-los" aos alunos, mas é o de ensiná-los a lidar com as informações e os conhecimentos que o mundo lhes propicia diariamente. (CAMPOS, 2014, p.21).

Cabe ao professor criar, na sala de aula, as condições para o desenvolvimento de atividades que possibilitem a cada estudante dialogar com o texto, interrogá-lo, explorá-lo; Participar enquanto leitor do texto privilegiado, mas sem autoritarismo, sempre receptivo às leituras dos estudantes, além de permitir-lhes, conforme o caso, o acesso às interpretações que a obra vem recebendo ao longo do tempo. Nesta perspectiva "para ler necessitamos simultaneamente manejar com destreza as habilidades de decodificação e aportar ao texto nossos objetivos, ideias e experiências prévias [..]" (SOLÉ, 1998, p. 23).

No ensino da Língua Portuguesa a gramática tem que estar a favor da leitura e da escrita, isto é, ela deve estar a serviço das práticas de linguagem, para que os alunos, conforme aprendam os conceitos que regem o funcionamento da língua, tornem-se críticos e conscientes das estratégias que possuem para compreender a leitura e se fazer entender por meio da escrita. 


\section{OS PCN'S E OS GÊNEROS TEXTUAIS: BREVE REFLEXÃO}

Já há muito tempo o texto é fundamentado no Ensino da Língua Portuguesa no Brasil, seja ele entendido como material destinado à leitura e ao estudo ou como algo que o aluno deve aprender a produzir. Por volta da década de 1980, o ensino tradicional dos gêneros escolares por excelência - a narração, a descrição e a dissertação - tipologia textual que frequentou por anos a fio (e que frequenta ainda) os programas curriculares de Português no Ensino Fundamental, passa a ser influenciado por noções da linguística textual.

Com a publicação dos Parâmetros Curriculares Nacionais (PCNs), em 1997 e 1998, surge um novo direcionamento para o ensino da Língua Portuguesa. A partir deste documento, as situações de produção e de circulação de textos estudados nas aulas de Língua Portuguesa passam a ter importância e se tornam um dos objetivos do ensino da disciplina. Os textos estão por toda parte em nossa sociedade e cada um deles apresenta uma especificidade, assim como um objetivo. Estes textos são organizados em tipologias e gêneros, os quais enunciam práticas sociais bem definidas.

Todo texto se organiza dentro de um determinado gênero. Os vários gêneros existentes, por sua vez constituem formas relativamente estáveis de enunciado, disponíveis na cultura, caracterizados por três elementos: conteúdo temático, estilo e construção composicional. Podese ainda afirmar que a noção de gênero se refere a "famílias" de textos que compartilham algumas características comuns, embora heterogêneas, como visão geral da qual o texto se articula, tipo de suporte comunicativo, extensão, grau de literariedade, por exemplo, existindo quase em número ilimitado. (BRASIL, MEC/SEF, PCNs 2001, p.26).

É importante destacar que nos referenciais utilizados pelos Parâmetros, a tipologia textual não é desprezada ou abandonada, mas incorporada ao estudo dos gêneros, constituídos por sequências tipológicas. O contexto de produção de gênero e sua função social passam a ter muita importância e o enfoque o ensino da linguagem e do ensino de gêneros orais formais públicos é valorizado. É a partir do trabalho com os gêneros textuais nas aulas de Língua Portuguesa, que os estudantes terão uma 
perspectiva adequada das exigências sociais, para que se tornem cidadãos capazes de comunicar-se, agir e intervir positivamente nas situações e resoluções de problemas diários da vida.

\section{OS GÊNEROS TEXTUAIS NA SALA DE AULA E O INCENTIVO À LEITURA}

O sentido da leitura não é restrito às letras impressas numa página de papel: os astrólogos leem as estrelas para prever o futuro; o músico lê a partitura para tocar seu instrumento; o médico lê a doença em seu paciente; a mãe lê a necessidade no rosto de seu bebê. Enfim, todas essas maneiras de leitura estão associadas à possibilidade de decifrar, traduzir signos e ler o mundo.

O mesmo acontece quando lemos as letras em variados suportes. A leitura do nome do ônibus que vamos pegar, de um jornal ou uma revista, de e-mail, de um livro de literatura, de um bilhete ou de uma conta de luz exigem diferentes níveis de concentração e são movidas por interesses diversos, despertando sentimentos também diversos. Além disso, há uma diversidade entre os livros que lemos: há aqueles que são de estudo, os que estão sempre sendo relidos, há os livros de bolso que carregamos para nos divertir, os livros difíceis que precisamos quase traduzir. Diferentes tipos de livros também pedem leituras diversas umas das outras. Nesse sentido Isabel Solé (1998, p. 93) nos lembra que

Os objetivos dos leitores com relação a um texto podem ser muito variados, e ainda que os enumerássemos nunca poderíamos pretender que nossa lista fosse exaustiva; haverá tantos objetivos como leitores, em diferentes situações e momentos.

A autora cita alguns exemplos de objetivos da leitura como, ler para obter uma informação precisa; ler para seguir instruções; ler para aprender, dentre outros. Todos esses exemplos de "para que ler?" nos remetem à consciência da relação dialógica entre a leitura e o ensino desta, levando o leitor aos círculos sociais intrínsecos e inseparáveis de compartilhamento da realidade. A partir dessas afirmativas podemos indagar: como a leitura vem sendo praticada nas escolas e, especificamente nas aulas 
de Língua Portuguesa? Quais são os critérios para as escolhas textuais que o professor utiliza em sala de aula?

As possibilidades de leitura em seus diversos gêneros textuais devem ser ampliadas para além dos livros de literatura (de autores consagrados ou não) e/ou didáticos. Os textos multimodais socialmente circundantes devem ser explorados, a fim de que os alunos tomem consciência das diferentes linguagens tecidas na comunicação humana em diferentes contextos. É preciso criar situações em que os alunos pensem sobre as atividades cotidianas que exigirão deles uma efetiva leitura como, por exemplo, pesquisar em jornais a sinopse de um filme em cartaz.

Unir os conceitos de gênero textual e práticas de linguagem nos encaminhamentos didáticos certamente produz aprendizagens duradouras, já que legitima as ações dos estudantes em torno da língua, isto é, permite-lhes experimentar, no contexto escolar, situações de leitura, escrita e oralidade semelhantes às que certamente enfrentarão na sociedade, fora dos muros da escola. (TAVARES, 2012, p. 67).

É pela via da interação e do diálogo que o professor vai repensar as práticas de leitura na escola enquanto mediador entre textos e leitores. O professor mediador também age como um facilitador da aprendizagem e, no ensino da leitura, este é o principal estimulador para o hábito de ler. Pela postura ativa em sala de aula compartilhando textos lidos, informando resenhas, lendo, explanando e dando exemplos, explorando alternativas de leitura, ele o estimulador-professor acaba por conquistar o prazer de ler em seus alunos em primeiro plano e, naturalmente, consegue explorar os diversos gêneros com suas funções sociais.

O trabalho explícito com os gêneros textuais é indispensável nas aulas de leitura. Na prática docente, o professor precisa apresentar aos alunos gêneros diversos para eles se familiarizarem com as formas distintas que os textos tomam para circular na sociedade. Por essa razão, realizar atividades de análise de gêneros é muito importante para atingir esse objetivo. Além disso, as atividades dão oportunidade ao professor de abordar dois elementos pragmáticos: a intencionalidade e a aceitabilidade [...] (OLIVEIRA, 2010, p. 86).

No trabalho com a leitura literária na sala de aula, deve-se considerar o que cabe nos reduzidos cinquenta minutos de uma aula ou tempo destinado a ela. Daí ser bem- 
vinda a escolha de gêneros mais curtos - crônicas, contos, poemas - para sessões de leitura seguidas de discussões ou outra atividade pelo grupo de alunos e professor. Para a leitura de livros realizada fora do ambiente escolar, o professor pode determinar datas para atividades de socialização dessas leituras, por meio de conversas sobre livros, da escrita de resenhas, blogs, murais, dentre outras que movimentem os circuitos dos livros na escola.

\section{A CRÔNICA: CONHECENDO O GÊNERO}

A palavra crônica vem da junção do termo grego "Khónos" ou latino "Chronos" que significa tempo. Em Língua Portuguesa, crônica tem acepção de comentário breve, publicado em jornal, revista ou mídia eletrônica. Essencialmente trata de fatos reais e/ou imaginários do cotidiano, influenciados por correntes impressionista e poético.

Nos primórdios da civilização portuguesa, houve a narrativa de fatos considerados importantes na esfera política e econômica. Posteriormente, esses registros foram organizados nos chamados Anais da História. Nesse contexto, as crônicas também tiveram um sentido estritamente histórico, visto que eternizaram os feitos dos reis e os noticiaram à posteridade. No final da Idade Média, o gênero atingiu o ápice com os relatos do cronista português Fernão Lopes (1418), que descreveu o governo dos reis D. Pedro I, D. Fernando e D. João I. Durante o Renascimento a crônica continuou como um texto de registro histórico.

A crônica recebeu os contornos literários que conhecemos, no início do século XIX, com o advento do Romantismo. A crônica brasileira estabelece-se no momento em que os jornais começaram a circular (a partir da vinda da família real) nas principais cidades.

Embora não derive dos gêneros estabelecidos desde a Antiguidade, a crônica tem dois antecedentes históricos: 1) o ensaio, um tipo de texto criado pelo francês Michel de Montaigne no século 16, que mescla experiência autobiográfica e reflexão sobre o mundo com uma lapidação estilística que transforma sua leitura em algo comparável à fruição de um romance; 2) o familiar essay de origem inglesa, gênero de comentário 
e devaneio pessoal veiculado em jornais pelos chamados "folhetinistas". (PINTO, 2005, p.9).

O gênero confirmou-se como sendo leve, que não tem a pretensão de durar, uma vez que é exposta, principalmente no jornal, meio de comunicação no qual tudo é veloz e perecível. Porém, ao longo dos anos a crônica foi se afastando da missão de informar e comentar, para se ater ao propósito de sensibilizar e divertir o leitor. A linguagem tornou-se mais despojada, afastando-se da lógica argumentativa e da crítica política.

Após a Semana de Arte de 1922, com a divulgação da estética modernista e sua consolidação, surgiu uma geração de cronistas no Brasil, entre os quais temos, Manuel Bandeira, Cecília Meireles, Carlos Drummond de Andrade, Rachel de Queiroz, Clarice Lispector dentre outros. O nome mais representativo da crônica contemporânea, contudo, é Rubem Braga, que iniciou sua carreira na década de 1930 e deu nova voz à crônica brasileira. A partir deste,

A crônica aparece como o lado positivo de nossa problemática identidade nacional: a uma realidade apequenada, sem alcance ou possibilidade de utopia, corresponde um gênero que dá cor e forma às miudezas da vida cotidiana, que encontra no humor, no deboche e na banalidade uma expressão saudável dessa informalidade social que, em outros momentos mascara desigualdades econômicas, autoritarismo e confusão entre as esferas pública e privada. Ironicamente, portanto, a crônica surge de uma espécie de complexo de inferioridade da sociedade e da literatura brasileiras, para se transformar num gênero autenticamente brasileiro, com um acervo de textos cujas riquezas poucas potências literárias conseguiram acumular. (PINTO, 2005, p.10).

A crônica brasileira guarda um caráter singular por seu estilo objetivo, que transcende seu suporte original devido ao seu lirismo. Atualmente, é possível encontrar crônicas dos melhores escritores do Brasil reunidas em livros e antologias.

Há crônicas que são dissertações, como em Machado de Assis; outras são poemas em prosa, como em Paulo Mendes Campos; outras são pequenos contos, como em Nelson Rodrigues; ou casos, como de Fernando Sabino; outras são evocações, como em Drummond e Rubem Braga; ou memórias e reflexões como em tantos. A crônica tem a mobilidade de aparências e de discursos que a poesia tem - e facilidade que a melhor poesia não se permite. (BRASIL/MEC, OLP, 2010). 
Por ser um gênero que muitas vezes, passa do jornalístico ao literário, é diversificado, flexível e de caráter híbrido, podendo usar a máscara de outros gêneros como a do conto, a da dissertação, a da memória, ou a da poesia. É despretensiosa e leve como uma conversa informal entre amigos, nos fazendo enxergar os pequenos detalhes do dia a dia, assim como as coisas belas e grandiosas.

\section{A LEITURA DE CRÔNICAS COMO FERRAMENTA DE ENSINO, NA FORMAÇÃO DE LEITORES DO $9^{\circ}$ ANO DA EDUCAÇÃO BÁSICA}

Ler e escrever, falar e ouvir não são atividades exclusivas de uma disciplina curricular - a de Língua Portuguesa - mas de todas, já que todo professor é mediador de linguagem. Um compromisso a ser assumido pela escola é o de possibilitar o aluno a aprendizagem dos diferentes textos que circulam socialmente e, um deles, é a crônica.

As crônicas tratam da realidade, do cotidiano, com linguagem despretensiosa e temas mais simples, geralmente relacionados ao passado e à infância. Por se tratar de um gênero mais cotidiano, confessional, breve e, sobretudo, muito vinculado à realidade do leitor, as crônicas são tidas como formas mais passageiras que a dos romances, contos e poesias. Nas aulas com alunos da Educação Básica (6ํㅜㅁ ao ano) é interessante começar o incentivo à leitura pelos textos mais simples, com palavras conhecidas, com temas próximos do universo do aluno, para ir gradativamente ampliando as possibilidades de leitura. A leitura é a habilidade que propicia autonomia no que diz respeito à compreensão do mundo e às múltiplas possibilidades de interpretar os fatos e desvendar, entre a infinidade de informações, com as quais somos bombardeados todos os dias, os valores, princípios, concepções que enriquecem nossa experiência pessoal. Assim, é importante colocar os alunos em contato com os vários tipos de temas abordados nas crônicas, assim como os mais literários - as crônicas de autores como Rubem Braga, Fernando Sabino e Carlos Drummond de Andrade. A matéria-prima do gênero crônica são as notícias curiosas, fatos comuns da convivência entre as pessoas e que podem acontecer com qualquer um. Esses acontecimentos propiciam momentos de nostalgia, enternecimento ou indignação compartilhados pelo cronista e o leitor. Através de suas muitas facetas 
como, as líricas, de humor, de ensaio, descritiva, narrativa, dissertativa, reflexiva ou metafísica, este gênero apresenta uma maneira singular que cada autor vê a vida, dando-Ihe um caráter encantador e literário. Assim, o panorama do cronista constituise num diálogo pessoal com objeto analisado de maneira leve, curta, muitas vezes objetiva em primeira pessoa, o que Ihe dá o aspecto pessoal e híbrido do gênero crônica.

Nessa concepção, a Revista Nova Escola abordou o tema intitulado "Quatro motivos para levar a crônica para a sala de aula", o qual transcrevemos abaixo.

1. A crônica narra eventos e, por isso, produzir este tipo de texto mobiliza algumas estruturas linguísticas próprias, como os verbos no pretérito perfeito e imperfeito e as formas narrativas em primeira pessoa.

2. Por apresentar uma narrativa curta, focada em temas cotidianos, as crônicas trazem um texto muito acessível do ponto de vista de leitura e da produção escrita. É por isso que as crônicas são um excelente ponto de partida para os exercícios de leitura e escrita em sala de aula, especialmente a partir do Fundamental 2.

3. Por meio da leitura desse gênero literário podemos iniciar os alunos na articulação dos tempos verbais do pretérito, verbos de estados e de transformação. É importante chamar a atenção dos alunos para o fato de que essa arquitetura textual tem uma forma mais ou menos estável e pode ser notada em quase todas as crônicas - o que faz disso um gênero.

4. Do ponto de vista da formação de leitores, é fundamental chamar a atenção dos alunos para o fato das crônicas depositarem um olhar sobre o cotidiano. (PORTILHO, online)

O Ministério da Educação do Brasil, em parceria com a Fundação Itaú Social, realiza um programa de caráter bienal e contínuo intitulado "Olimpíada da Língua Portuguesa". O objetivo é contribuir para a melhoria da leitura e escrita de alunos das escolas públicas de todo o país, através das sequências didáticas direcionadas a 
determinados gêneros textuais, no caso do 9. Ano do Ensino Fundamental e da 1. Série do Ensino Médio, a crônica. O programa envolve não somente professores e alunos dando-Ihes todo o suporte pedagógico necessário à execução do projeto, mas também os gestores educacionais locais, municipais e estaduais. Em anos ímpares o MEC/CEMPEC atendem esses gestores e técnicos das Secretarias de Educação que atuam como formadores, diretores, professores e, em anos pares, promovem um concurso de produção de texto para alunos do 5. e do 9. Anos do Ensino Fundamental. Trata-se de uma importante oportunidade a professores e alunos de aprimorarem a leitura e escrita, utilizando em uma das etapas de ensino, o gênero crônica, objeto de nosso presente estudo.

\section{METODOLOGIA}

O conhecimento descoberto através da pesquisa pode ser aplicado a muitas atividades cotidianas e profissionais, seja na solução de problemas, nas inquietações advindas do fazer prático, na convivência interpessoal, na formação de opiniões ou em muitas outras.

A metodologia da pesquisa possibilita, dentre outros, o alcance das respostas às perguntas e hipóteses formuladas. O método e as técnicas apresentam alguns itens da pesquisa que passaremos a especificar, como a natureza, a finalidade, a abordagem do problema, os objetivos e os procedimentos técnicos utilizados para o alcance dos resultados.

A natureza da presente pesquisa é a aplicada/exploratória, a qual visa gerar conhecimento para a aplicação prática através da proximidade com o problema, neste caso específico, a sala de aula, partindo de estudos teóricos sobre o tema proposto e avançando para os procedimentos de coletas de dados in loco. A finalidade pauta-se no alcance de respostas para o melhor aprendizado de alunos no 9 Ano do Ensino Fundamental e a consequente definição de estratégias pedagógicas no processo de ensino-aprendizagem, com vistas ao problema, formação de leitores críticos. Tal finalidade aponta para o alcance dos objetivos específicos da presente pesquisa, sintetizados pelos verbos determinar (as principais dificuldades), definir (estratégias 
utilizadas por professores no ensino da leitura) e apontar meios para melhorar a práxis de ensinar. A abordagem do problema dar-se-á mediante método indutivo (parte dos dados particulares para o geral) misto, sendo questionário quantitativo fechado (5 perguntas) aos alunos de uma única turma de aproximadamente 35 adolescentes e questionário aberto (6 perguntas) aplicado a dois professores da área de letras. Assim, os procedimentos técnicos perpassam pela pesquisa bibliográfica e o levantamento de dados.

\section{RESULTADOS E DISCUSSÃO}

A apresentação e discussão dos resultados consistem na interpretação analítica dos dados obtidos, com base no problema identificado, nos teóricos estudados e nos objetivos propostos. Esta pesquisa apresenta a metodologia exploratória, com abordagem mista indutiva, questionário objetivo fechado aos alunos (29) e qualitativo direcionado a dois professores. A primeira análise refere-se à abordagem quantitativa de questionário fechado com cinco perguntas aos alunos. Para tal apresentamos, o questionário na integral e, na sequência, a tabulação dos dados por respostas e seus respectivos gráficos comentados.

\subsection{ANÁlise DOS RESULTADOS DA PRIMEIRA PARTE DA PESQUISA - QUESTIONÁRIO FECHADO AOS ALUNOS}

Gráfico 1 - Conhecimento do gênero crônica

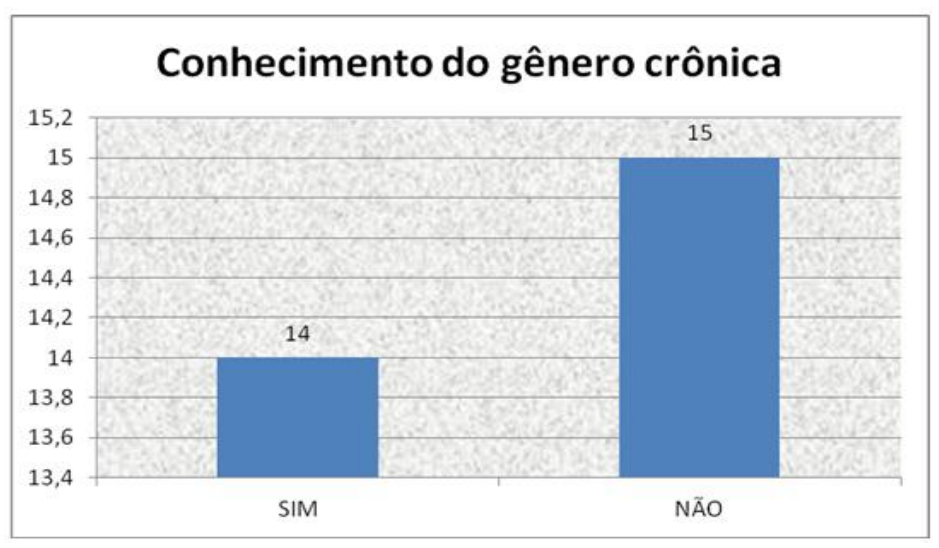

Fonte: elaborado pela autora, ano 2015. 
O questionamento um tem por finalidade saber se os alunos afirmam ou negam o 0 próprio conceito de uma crônica, isto é, a estrutura do gênero que permiti-lhes identificá-lo como uma crônica. Dos vinte e nove alunos pesquisados quatorze (14) afirmaram que sim e quinze (15) afirmaram que não. Isto evidencia que o gênero é pouco explorado em sala de aula ou se é apresentado aos alunos não se faz menção da estrutura textual trabalhada.

Isabel Solé (1998), afirma que quando lemos temos objetivos variados e, estes devem ser definidos no momento em que entramos em contato com o texto. Se o professor oportuniza a antecipação ao texto, explorando suas características enquanto gênero, o leitor formula previamente seu objetivo de ler, independente do proposito pedagógico, se para verificar o que aprendeu, praticar leitura em voz alta ou apenas ler por prazer, dentre outros.

Gráfico 2 - Utilização da crônica em sala de aula pelo professor

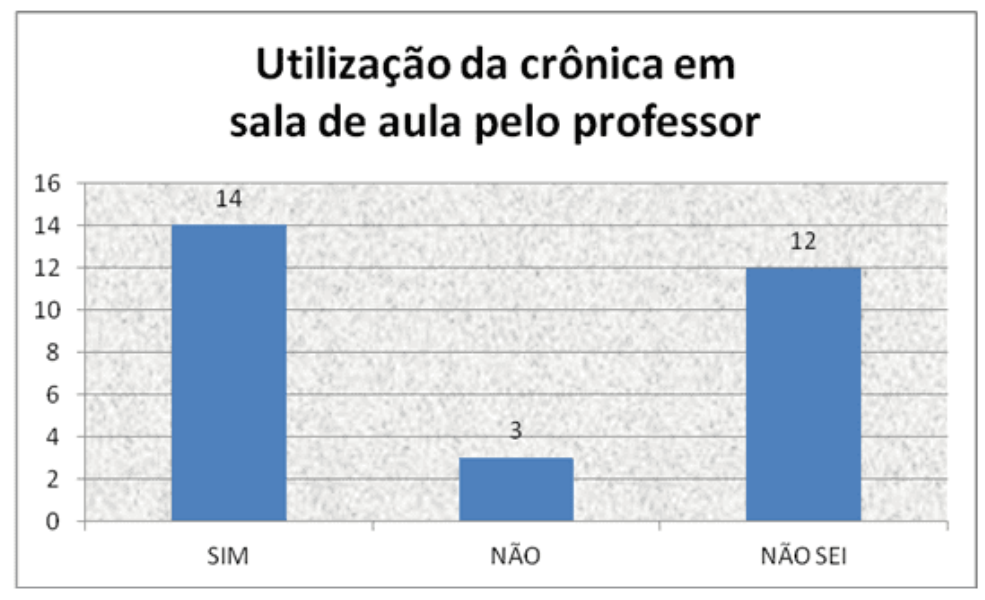

Fonte: Elaborado pela autora, ano 2015.

No questionamento dois, exatamente quatorze alunos afirmaram que seu professor de Língua Portuguesa já apresentou o gênero crônica em sala de aula. Comparando este dado específico com a variante (sim) do questionamento um, observamos que há coerência entre as respostas, uma vez que exatamente quatorze alunos conceituam crônica. Analisando as respostas supomos que esta parcela da turma de $48,2 \%$ tem plena consciência do gênero e de sua utilização pelo professor. 
As demais respostas deste item mostram que: doze alunos, isto é, 41,3\% deles, não está consciente do gênero textual trabalhado nas aulas de Língua Portuguesa; três alunos (10,3\%) afirmam que o professor ainda não utilizou a crônica nas aulas. As respostas nos levam a refletir sobre o prazer da leitura transmitido pelo professor aos alunos. Nesse contexto, “(...) seria preciso distinguir situações em que se trabalha a leitura e situações em que simplesmente se lê" (SOLĖ, 1998, p. 90).

Gráfico 3 - Suporte do gênero crônica

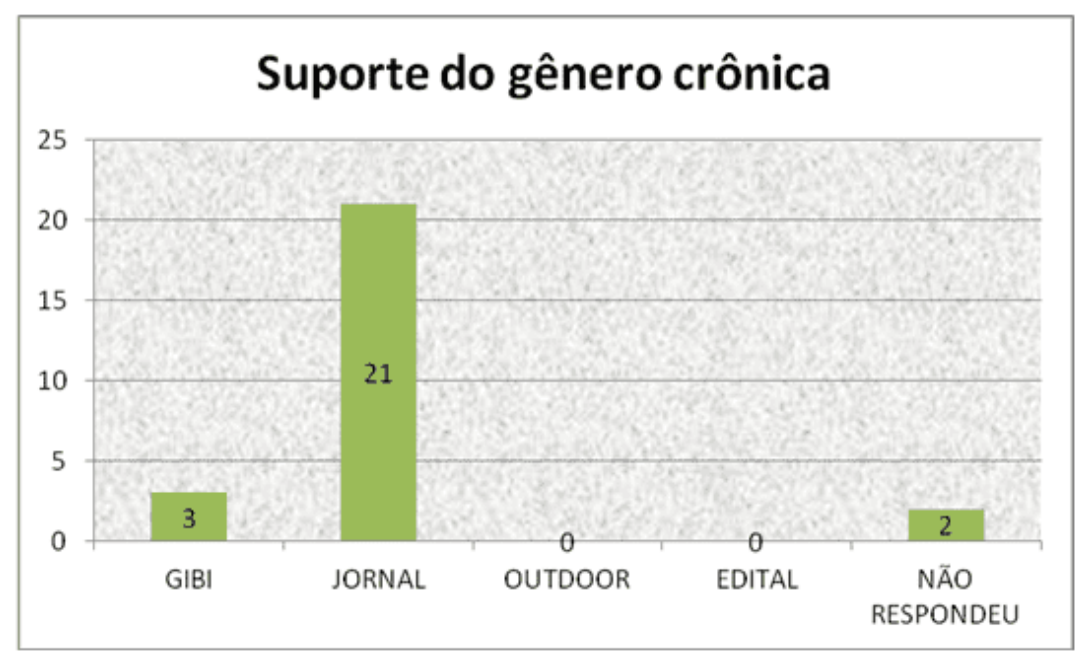

Fonte: Elaborado pela autora, ano 2015.

No questionamento três abordamos o suporte da crônica. Tal abordagem nos remete ao uso social do texto e seu veículo de expressão. Dos vinte e nove participantes da pesquisa 74,4\%, exatamente vinte e um alunos, reconhecem este uso. Dois dos alunos não responderam e três deles, 10,3\%, apontaram o gibi como suporte para uma crônica. A maioria dos alunos tem consciência de que um texto crônica não poderia ser veiculado em outdoor, edital ou gibi. Os PCN's em seu volume 2, p. 23 de Língua Portuguesa, apontam que

O domínio da língua tem estreita relação com a possibilidade plena participação social, pois é por meio dela que o homem se comunica, tem acesso à informação, expressa e defende pontos de vista, partilha e constrói visão de mundo, produz conhecimento. 
O reconhecimento do suporte de um determinado gênero textual, no caso a crônica, evidencia conhecimento de mundo por parte dos alunos, não se limitando a conceitos factuais ou pontuais.

Gráfico 4 - Principal dificuldade dos alunos na produção textual

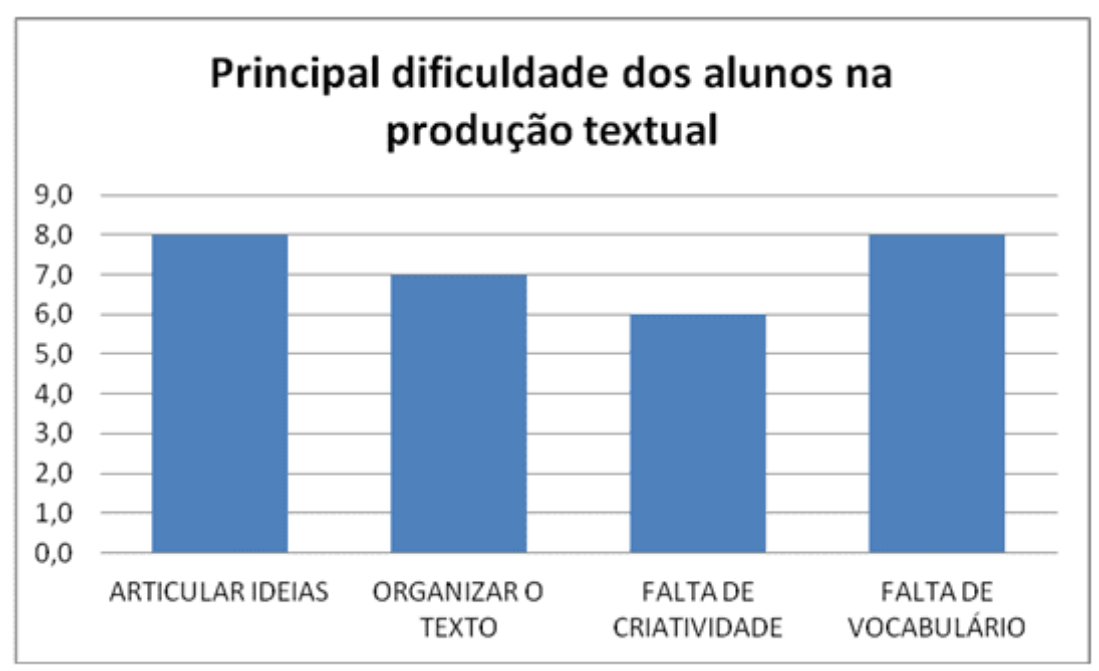

Fonte: Elaborado pela autora, ano 2015.

No quarto questionamento as variantes articular ideias $(27,5 \%)$, falta de criatividade $(20,6 \%)$ e falta de vocabulário $(27,5 \%)$ evidenciam deficiências na regularidade de leitura por parte dos alunos, uma vez que a formação de um leitor não é um processo espontâneo, nem natural. A leitura está intimamente ligada à escrita e, para compreender os muitos sentidos do texto, além de participar de uma comunidade de leitores, nesse caso a escola, é preciso ter contato com leitores mais experientes.

Por outro lado, 24,13\% responderam que sua principal dificuldade ao produzir textos se remete à organização estrutural dos mesmos. Essa parcela dos alunos apresenta, pelas respostas elencadas, lacunas na prática da escrita, o que não deixa de ser indiretamente, consequência da falta de regularidade leitora. 
Gráfico 5 - A leitura ajuda a desenvolver a escrita de bons textos

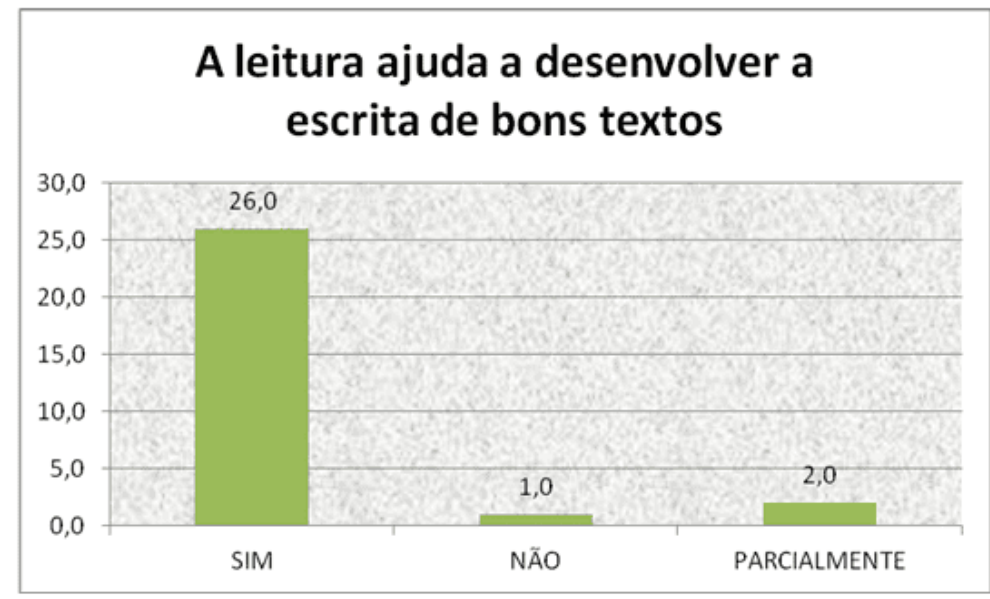

Fonte: Elaborado pela autora, ano 2015.

Uma grande parcela dos vinte e nove alunos pesquisados (89,6\%) concorda com a afirmativa de que a leitura é o eixo norteador do ensino-aprendizagem e, contribui significativamente para o desenvolvimento cognitivo (raciocínio de ideias, criatividade, criticidade), assim como para o desenvolvimento na escrita de textos e, consequentemente, para o efetivo exercício da cidadania. Segundo os PCN's (V. 2 p. 53) leitor competente é aquele que

realiza um trabalho ativo de construção de significados do texto, a partir de seus objetivos, de seu conhecimento sobre o assunto, sobre o autor, de tudo o que se sabe sobre a língua: características de gênero, do portador, do sistema de escrita etc.

As demais respostas, NÃO $(3,4 \%)$ e PARCIALMENTE $(6,8 \%)$ evidenciam que estes alunos ainda não foram conscientizados da importância do ato de ler para o êxito em qualquer área da vida.

\subsection{SEGUNDA PARTE DA PESQUISA: ASPECTO QUALITATIVO}

O questionário qualitativo foi aplicado a duas professoras formadas em Letras, ambas docentes da Escola Estadual Maria Calderaro em Presidente Figueiredo-AM, atuando há mais de cinco anos no Ensino Fundamental 2. A seguir, passaremos a elencar as 
respostas dadas e a discutir os resultados à luz do embasamento teórico apresentado neste trabalho.

\subsubsection{Análise das respostas do questionário aberto}

Tabela 1 - Questionário aberto aos professores

\section{VARIANTES}

1. Utilização da crônica Utilizo as vezes. nas aulas

2. Características da Narração curta; humor, Texto curto de linguagem crônica ironia, criticidade e rebuscada. Pode ter sátira; coloquialismo; humor, sátira e ironia. fatos do cotidiano.

3. Comentário sobre a Sim, pois em cada Sim, de certo modo por ser citação: "A crônica é uma narrativa que você uma leitura que envolve o espécie de lupa que você expõe tem fatos leitor, uma vez que a coloca em um assunto". corriqueiros do dia a dia pessoa aproxima-se do (PRATA, e se encaixam 2015). Concorda? perfeitamente no Justifique. contexto da crônica.

Fatos do dia a dia. Oralidade. autor como se estivesse em uma conversa informal. O cronista tende a dialogar sobre fatos íntimos com o leitor.

\section{Crônica: gênero Sim. Sim.}

\section{literário?}

5. A crônica é um gênero Sim, por ser uma Com certeza, por ser um interessante para narrativa curta, que não texto curto de linguagem favorecer o hábito da se torna cansativa e simples, prazeroso para leitura? enfadonha. todas as faixas etárias. Também por ser satírico, irônico, onde os 


\section{personagens}

expressam

sentimentos.

6. Aponte a maior Os alunos não gostam É o desinteresse total dos dificuldade encontrada de ler leituras indicadas, alunos, principalmente por você no trabalho com livros. A biblioteca quando chegam ao 9. Ano, a leitura e produção muitas vezes, não pois acham que não textual de alunos do 9 o dispõe de livros para precisam mais da leitura. Ano do Ensino atrair a clientela, que Infelizmente essa é a Fundamental. gosta de aventura e nossa realidade. muita emoção.

Fonte: Elaborado pela autora, ano 2015.

Ao analisar as respostas elencadas na tabela 1, observa-se que, tanto a professora 1 como a professora 2, dominam o conhecimento do gênero textual crônica, reconhecendo sua consagração na literatura brasileira, assim como concordam opinativamente que a crônica seria um gênero interessante para estimular a leitura em sala de aula. Porém, ambas somente utilizam o gênero em sala de aula esporadicamente, o que corrobora para que $51,6 \%$ dos alunos não o reconheçam quando está sendo utilizado pelo professor, como demonstra o gráfico 2 do questionário fechado direcionado aos alunos.

Ao serem convidados a comentar a citação de Prata, 2015 sobre a crônica como uma espécie de lupa ao assunto, apenas a professora 2 sinalizou de forma breve o detalhamento do cotidiano que a crônica oferece ao leitor. No item 6 da tabela 1, observamos que a dificuldade de leitura entre os alunos, na visão das professoras, é a falta de interesse em ler. Tal resultado nos remete às respostas elencadas no gráfico 4 do questionário fechado, em que $75,6 \%$ dos alunos elencaram opções de respostas às dificuldades de escrita relacionadas à falta do hábito de ler, como por exemplo, falta de criatividade para desenvolver um tema e articulação de ideias no papel. Nesse sentido a atuação do professor é essencial na formação de leitores críticos, conforme o que afirma Oliveira (2010, p.71), 
A função mediadora que o professor possui no desenvolvimento da competência de leitura dos estudantes é muito importante. Como mediador, cabe ao professor a tarefa de ajudar seus alunos a dominarem estratégias de leitura que Ihes sejam úteis nos atos de interpretação textual. Essas estratégias são ações procedimentais estreitamente vinculadas aos conhecimentos prévios dos estudantes, as quais precisam ser abordadas em sala de aula.

Entre as competência e habilidades que podem ajudar um adolescente a se tornar um cidadão crítico destaca-se a competência leitora e a formação de escritores, pois a possibilidade de produzir textos eficazes tem sua origem, na prática de leitura, espaço de construção de intertextualidade e fonte de referências norteadoras.

\section{CONSIDERAÇÕES FINAIS}

Quando falamos em leitura na escola, de ensinar e de aprender a ler, estamos pensando no tipo de leitura envolvida nesse processo. Disso advém o investimento subjetivo no leitor e na valorização de suas escolhas. Quando falamos do gênero crônica, do texto crônica, falamos e pensamos bem mais do que um emaranhado de palavras, frases, ou de conjecturas literárias; falamos de vida pulsante expressa em palavras. Pela crônica, estamos diante das experiências do homem comum, expressas em linguagem ordinária e publicadas regularmente nas páginas da imprensa, ou seja, nos movimentos criativos da vida pública que são, em primeira instância, os jornais e as revistas. Muitos autores renomados têm se dedicado a escrever crônicas, como Luis Fernando Veríssimo, Lourenço Diaféria, Domingos Pellegrini, tornando-a um gênero contemporâneo pela renovação de repertórios e fazendo-a profícua ao ensino e incentivo da leitura em sala de aula. Este trabalho possibilitou a redefinição do gênero como de suma importância no trabalho docente de incentivo à leitura e, consequentemente na formação de leitores críticos. Possibilitou ainda, a definição de métodos e o conhecimento do fazer pedagógico de dois profissionais da área de Letras no Ensino Fundamental na escola pesquisada. Determinamos quais as principais dificuldades encontradas no trabalho com o gênero crônica com o intuito de formar leitores críticos. Conhecemos qual o olhar, direcionado a este gênero literário, de alguns dos alunos adolescentes do 9. ano do Ensino Fundamental. Tais objetivos foram alcançados, porém o tema não foi e nem poderia 
ser esgotado, pois concluímos que a crônica estaria sendo pouco explorada em sala de aula. Daí advém a sugestão de prosseguir com o tema da pesquisa, enfocando estratégias didáticas para que a crônica seja mais conhecida e utilizada como texto estratégico na formação do leitor crítico, já que possibilita total liberdade, no sentido de criar e perpassar gêneros variados, inclusive o opinativo. As dificuldades na condução da pesquisa foram mínimas e praticamente não houve pontos negativos. Registrou-se aceitação por partes das pessoas envolvidas quanto a todo o trabalho realizado.

\section{REFERÊNCIAS}

BRASIL.MEC. Olimpíada de Língua Portuguesa. A ocasião faz o escritor: caderno do professor. São Paulo: CENPEC, 2010.

BRASIL. SEF/MEC. Parâmetros curriculares nacionais: língua portuguesa. V. 2. Brasília, 2001.

CAMPOS, Elísia Paixão de. Por um novo ensino de gramática: orientações didáticas e sugestões de atividades. Goiânia: Cânone Editorial, 2014.

OLIVEIRA, Luciano Amaral. Coisas que todo professor de português precisa saber: a teoria na prática. São Paulo: Parábola Editoral, 2010.

PORTILHO, Gabriela. Leve a crônica para as aulas de Língua Portuguesa. Nova Escola versão eletrônica disponível em <http://revistaescola.abril.com.br/ fundamental-2/leve-cronica-aulas-lingua-portuguesa-730805.shtml?page=2>

PINTO, Manuel da Costa (Org.) Crônica Brasileira Contemporânea (Antologia). 1. ed. São Paulo: Moderna, 2005.

SOLÉ, Isabel. Estratégias de Leitura. Tradução Cláudia Schilling. 6. ed. Porto Alegre: Artmed, 1998. 
TAVARES, Cristiane et. al. Guia Nós da Sala de Aula. (vários autores) Organização Heloisa Ramos. 1 ed. São Paulo: Ática, 2012.

Enviado: Março, 2020.

Aprovado: Novembro, 2020. 